Research Article

\title{
The Use of Waste Maroon Marble Powder and Iron Oxide Pigment in the Production of Coloured Self-Compacting Concrete
}

\author{
Mucteba Uysal 1 \\ Civil Engineering Department, Engineering Faculty, Istanbul University, Avcilar, Istanbul, Turkey \\ Correspondence should be addressed to Mucteba Uysal; mucteba.uysal@istanbul.edu.tr
}

Received 25 August 2017; Accepted 11 January 2018; Published 29 March 2018

Academic Editor: Venu G. M. Annamdas

Copyright (c) 2018 Mucteba Uysal. This is an open access article distributed under the Creative Commons Attribution License, which permits unrestricted use, distribution, and reproduction in any medium, provided the original work is properly cited.

\begin{abstract}
This work covers some workability, mechanical, and durability properties of coloured self-compacting concrete (SCC) containing maroon marble powder and iron oxide pigment. Pigments with varying amounts were used to produce coloured SCC. For this purpose, ten different series were prepared of which two of the series were pigment free that one of them was the colour of white SCC including limestone powder and the other one was the colour of maroon SCC including maroon marble powder. The other series were containing pigments with varying amounts. The water to binder ratio remained constant for all the series at 0.42 . Slump flow, T50 time, V-funnel, and L-box tests were used to determine the workability of coloured SCC. The hardened properties that were determined included density, water absorption, ultrasonic pulse velocity (UPV), compressive strength, abrasion resistance, and impermeability. As workability, experimental results showed that coloured SCC could be obtained by using maroon marble powder and when iron oxide pigment used in amounts less than $6 \%$. The addition of pigment notably increased the water absorption of SCC series. The use of smaller quantities of pigment caused slight increase in compressive strength. Higher pigment content also provided decreases in abrasive resistance, and after exposure to abrasion, mass losses were within the range of $0.89 \%-2.12 \%$ and the abrasion depths were within the range of $0.9 \mathrm{~mm}-2.1 \mathrm{~mm}$. Among the varying amounts of pigmented series, M1 series which contains $1 \%$ pigment showed the best performance, and the findings indicated that it is possible to successfully utilize maroon marble powder and lower amounts of pigments in producing coloured SCC.
\end{abstract}

\section{Introduction}

As a specially designed concrete, self-compacting concrete (SCC) is a kind of high-performance concrete that can spread in areas of difficult access readily and consolidate into place under its own weight. It can pass through the gaps between the reinforcement bars to fill the formwork completely. SCC also can maintain its stable composition simultaneously without the need of mechanical consolidation and without undergoing any significant separation of material constituents http://www. sciencedirect.com/science/article/pii/S095006181730541X [1-4]. Because of the excellent workability properties of fresh SCC, resulted in good mechanic and durability properties of hardened concrete. Since it was initially developed in Japan in 1980's, SCC got more attention and now SCC has broken fresh ground in modern concrete technology http://www. sciencedirect.com/science/article/pii/S0950061817305354 [5]. SCC provides a shorter construction time, produces a good surface finish, and provides greater freedom in architectural and aesthetic designs; production of SCC is environmentally friendly because of no noise. SCC is typically associated with low content of coarse aggregates and w/b ratio, and high content of binder, powders, fine aggregates, and plasticizing admixtures.

Architectural concrete is a fantastic topic. Architectural concrete is nonstructural or structural concrete that will be perennially exposed to view and needs special attention for this reason to material uniformity, forming, placing, and finishing to obtain the desired architectural and decorative appearance. Examples of applications are buildings and transportation structures like highway sound/barrier walls, bridges, concrete pavers, concrete roof tiles, pathways, and prefabricated concrete products. Especially in Turkey, concrete parquets are commonly used in urbanization projects for road paving and red-coloured parquets that are used in particular for road marking or road lines can be 


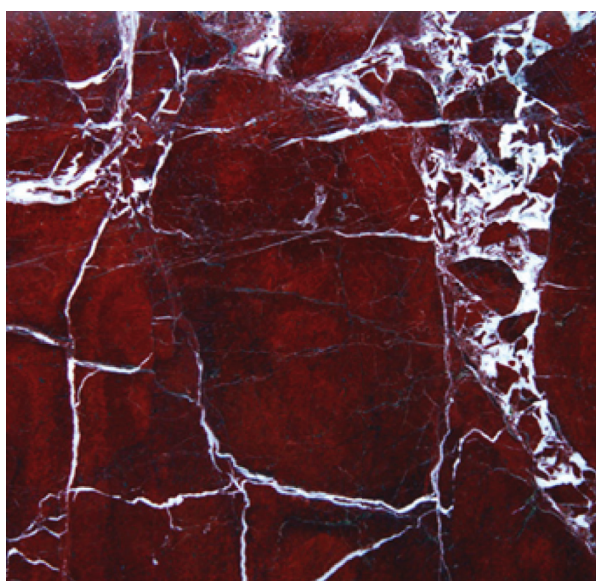

(a)

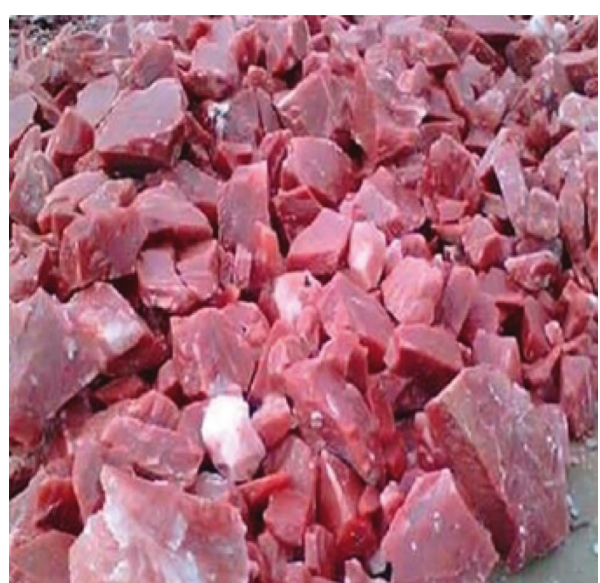

(b)

FIGURE 1: Elazig maroon marble block (a) and shredded maroon marble resembles cubed meat (b).

found along the road or across the road to provide awareness to hazards and to give drivers directions or for rules. Pigments are commonly used for permanent colouring of concrete that is to paint it a colour different from the natural colour of the cement or the various aggregates.

The development of coloured SCC leads to open new areas of application of SCC since it provides attractive alternatives for challenging architectural designs and applications in terms of colour and shapes, to the already all-purpose aesthetic and decorative characteristics of conventional coloured concrete. In addition to the advantages of SCC's fluidity and filling capacity, the coloured SCC enables the aesthetic and decorative aspects from a variety of colours and surface textures. In the literature, some recent applications of coloured SCC can be found [6].

Marble has been used as an architectural decoration to embellish the floors, walls of temples, and public areas since ancient times. It is one of the most widely used decorative and aesthetic pleasing stones all over the world. Turkey has wide resources since it is located in the Alps mountain range, in terms of natural stones. With its 4,000 years of background in marble production, Turkey has been one of the oldest marble producers in the world. Having a remarkable and variety of mineral bases, it has one of the world's largest natural stone reserves and approximately five billion $\mathrm{m}^{3}$ of valuable marble reserve and has $40 \%$ of the world marble potential [7, 8]. Maroon marble (Elazig cherry) is made of carbonated ultrabasic rocks, serpentinite (Figure 1) and red-green pebbles are attached with the same-coloured cement.

As a by-product of stone crushers, a considerable amount of limestone powder is produced in limestone quarries. Large quantities of powders are accumulated and the use of these by-products has serious problems in terms of environmental pollution, disposal of waste, and public health hazard [9]. Additionally, marble manufacturing industry leads to much waste production [10]. The waste of maroon marble powder can also cause environmental problem for ecosystem and economic loss if the waste is not recycled, and SCC technology has a great potential for such solid wastes. SCC is one of the most attractive alternatives utilizing the limestone and maroon marble powder in the concrete industry. The effect of marble powder on the mechanical properties of hardened concrete has been investigated by many researchers, and the use of marble powder in the production of SCC will be expected to become more widespread in the future [11-16].

The aim of this study is to investigate the effect of maroon marble powder and iron oxide pigments on the some workability, mechanical, and durability properties of SCC. For this purpose, slump flow, $T_{50}$ time, $\mathrm{V}$-funnel time, and L-box ratio tests were performed in terms of workability. Hardened concrete tests were performed such as compressive strength, density, water absorption, and ultrasonic pulse velocity as a performance of maroon marble powder and pigments. Moreover, the abrasion resistance and impermeability of SCC mixtures are investigated. Although these pigments are widely used, a few research has been carried out for the usability of a natural waste (contains no synthetic dyes) to colour the SCC. Experimental results aimed the usability of maroon marble powder as a natural waste in the production of coloured SCC and at recommending optimum amount of pigments for using in the production of SCC in respect to workability, mechanic and durability properties.

\section{Experimental}

2.1. Materials. In this study, some materials used include crushed limestone coarse aggregate with the specific gravity of 2.67 and water absorption of $0.24 \%$, a natural river sand with the specific gravity of 2.60 and water absorption of $1.48 \%$, white Portland cement, chemical admixture, and powders. A crushed limestone coarse aggregate and natural river sand, and with a maximum particle size of $16 \mathrm{~mm}$ were used as coarse and fine aggregates, respectively. The type of cement used in all SCC series was white Portland cement which is complied with EN 197-1 and labeled as CEM I 52.5 R. 28th day compressive strength and specific surface area by Blaine of cement were $60.0 \mathrm{MPa}$ and $4600 \mathrm{~cm}^{2} / \mathrm{g}$, respectively. Moreover, limestone powder is used to obtain self-compactability 
TABLE 1: Mechanical, physical, and chemical properties of cement and mineral admixtures.

\begin{tabular}{|c|c|c|c|}
\hline Component (\%) & Cement & MMP & LP \\
\hline $\mathrm{SiO}_{2}$ & 21.60 & 0.68 & 4.94 \\
\hline $\mathrm{Fe}_{2} \mathrm{O}_{3}$ & 0.26 & 0.17 & 0.57 \\
\hline $\mathrm{AI}_{2} \mathrm{O}_{3}$ & 4.05 & 0.32 & 0.81 \\
\hline $\mathrm{CaO}$ & 65.7 & 56.25 & 51.96 \\
\hline $\mathrm{MgO}$ & 1.30 & 0.21 & 0.57 \\
\hline $\mathrm{SO}_{3}$ & 3.30 & - & - \\
\hline $\mathrm{CI}^{-}$ & - & - & - \\
\hline $\mathrm{K}_{2} \mathrm{O}$ & 0.35 & 1.80 & - \\
\hline $\mathrm{Na}_{2} \mathrm{O}$ & 0.30 & 2.44 & - \\
\hline Loss ignition & 3.20 & 42.83 & 40.39 \\
\hline Specific gravity & 3.06 & 2.73 & 2.71 \\
\hline Blaine $\left(\mathrm{cm}^{2} / \mathrm{g}\right)$ & 4600 & 8031 & 2500 \\
\hline \multicolumn{4}{|c|}{ Compressive strength (MPa) } \\
\hline 2 days & 37.0 & & \\
\hline 7 days & 50.0 & & \\
\hline 28 days & 60.0 & & \\
\hline
\end{tabular}

TABle 2: Physical and chemical properties of pigment.

\begin{tabular}{|c|c|c|c|c|c|c|c|}
\hline $\begin{array}{l}\text { Pigment } \\
\text { type }\end{array}$ & $\begin{array}{c}\text { Water } \\
\text { absorption } \\
(\mathrm{g} / 100 \mathrm{~g})\end{array}$ & $\begin{array}{c}\text { Apparent } \\
\text { density } \\
\left(\mathrm{g} / \mathrm{cm}^{3}\right)\end{array}$ & $\begin{array}{l}\text { Remaining on the } \\
\text { sieve } 45 \mu \mathrm{m}(\%)\end{array}$ & Composition & $\begin{array}{c}\text { Percentage of salt } \\
\text { soluble in water }(\%)\end{array}$ & Density & $\begin{array}{l}\text { Dominant particle } \\
\text { size } \%(\mu \mathrm{m})\end{array}$ \\
\hline $\begin{array}{l}\text { Bayferrox } \\
\text { red } 110 \mathrm{C} \\
\end{array}$ & 35 & $0.7-1.1$ & 0.06 & $\begin{array}{c}94-96 \% \\
\mathrm{Fe}_{2} \mathrm{O}_{3}\end{array}$ & 0.5 & 5.0 & 0.09 \\
\hline
\end{tabular}

TABLE 3: Mix proportions of SCC mixtures.

\begin{tabular}{lcccccccccc}
\hline Mixtures & $\begin{array}{c}\text { Cement } \\
\left(\mathrm{kg} / \mathrm{m}^{3}\right)\end{array}$ & $\begin{array}{c}\mathrm{LP} \\
\left(\mathrm{kg} / \mathrm{m}^{3}\right)\end{array}$ & $\begin{array}{c}\mathrm{MP} \\
\left(\mathrm{kg} / \mathrm{m}^{3}\right)\end{array}$ & $\mathrm{w} / \mathrm{p}$ & $\mathrm{w} / \mathrm{c}$ & $\begin{array}{c}\text { Water } \\
\left(\mathrm{lt} / \mathrm{m}^{3}\right)\end{array}$ & $\begin{array}{c}\text { CSI } \\
\left(\mathrm{kg} / \mathrm{m}^{3}\right)\end{array}$ & $\begin{array}{c}\text { CSII } \\
\left(\mathrm{kg} / \mathrm{m}^{3}\right)\end{array}$ & $\begin{array}{c}\text { Sand } \\
\left(\mathrm{kg} / \mathrm{m}^{3}\right)\end{array}$ & $\begin{array}{c}\text { Pigment } \\
\left(\mathrm{kg} / \mathrm{m}^{3}\right)\end{array}$ \\
\hline M1 & 420 & 180 & - & 0.29 & 0.42 & 176 & 507 & 321 & 789 & - \\
M2 & 420 & - & 180 & 0.29 & 0.42 & 176 & 497 & 315 & 795 & - \\
M3 & 420 & 180 & - & 0.29 & 0.42 & 176 & 491 & 311 & 807 & 4.20 \\
M4 & 420 & 180 & - & 0.29 & 0.42 & 176 & 485 & 307 & 816 & 8.40 \\
M5 & 420 & 180 & - & 0.29 & 0.42 & 176 & 505 & 320 & 791 & 12.60 \\
M6 & 420 & 180 & - & 0.29 & 0.42 & 176 & 503 & 319 & 792 & 16.80 \\
M7 & 420 & 180 & - & 0.29 & 0.42 & 176 & 501 & 318 & 799 & 21.00 \\
M8 & 420 & 180 & - & 0.29 & 0.42 & 176 & 505 & 320 & 793 & 25.20 \\
M9 & 420 & 180 & - & 0.29 & 0.42 & 176 & 503 & 319 & 788 & 29.40 \\
M10 & 420 & 180 & - & 0.29 & 0.42 & 176 & 502 & 317 & 791 & 33.60 \\
\hline
\end{tabular}

of SCC, and maroon marble powder is used to colour SCC mixtures without pigments. Maroon marble powder (MMP) directly used in SCC without any processes was provided with a marble managing plant in Elazig. Limestone powder (LP) is a by-product of quarry crushers and collected from the filtration system of quarry crushers. The chemical, physical, and mechanical characteristics of mineral admixtures and white Portland cement used in this study are presented in Table 1. Some pigment characteristics used in this study are presented in Table 2.

2.2. Mixture Composition. Ten series of mix proportions were prepared of which two of the series were pigment free that one of them was the colour of white SCC including limestone powder (M1) and the other one was the colour of maroon SCC including maroon marble powder (M2). The other series that were containing pigments with varying amounts were prepared. The proportions of the produced mixtures are given in Table 3. The mixtures were coded such that the ingredients were identifiable from their IDs as seen in the table. Pigments were used 1\% (M3), 2\% (M4), 3\% (M5), 4\% (M6), 5\% (M7), 6\% (M8), 7\% (M9) and 8\% (M10) of cement weight in eight series of SCC. Crushed stone number I (CSI) aggregate which has a particle size of $5 \mathrm{~mm}-12 \mathrm{~mm}$ and crushed stone number II (CSII) aggregate which has a particle size of $12 \mathrm{~mm}-16 \mathrm{~mm}$ were used in this study. The total amount of powder was selected to be $600 \mathrm{~kg} / \mathrm{m}^{3}$, and the water-powder ratio (w/p) was fixed as 0.29 after the preliminary investigations. A $50 \mathrm{dm}^{3}$ batch has been prepared for each series. A new generation polycarboxylic ether-based superplasticizer was also used which 
has 1.08 specific gravity, $8.1 \mathrm{pH}$, and $23.9 \%$ solid content. To provide desired fluidity of SCC, superplasticizer was employed at the ratio of $2.06 \%$ of binder materials by weight to reduce the water/binder ratio of SCC mixtures.

2.3. Casting, Curing, and Testing of Specimens. Density, water absorption, UPV, and compressive strength measurements were performed on $100 \mathrm{~mm}$ cube specimens. Before performing hardened concrete tests, all specimens, with or without pigments, were cured in water at $20 \pm 2^{\circ} \mathrm{C}$ and $60 \% \mathrm{RH}$. The specimens were then cast in molds, and other than their own self-weights were not exposed to any compaction. To analyze some workability properties of SCC mixtures, slump flow diameter, $T_{50}$ time, $V$-funnel time, and L-box ratio tests were performed complied with EFNARC Committee's suggestions [17]. Water absorption, compressive strength, and UPV tests were performed on hardened concrete at 3,7 , and 28 days, whereas density was monitored at 28 days.

Water absorption properties of SCC mixtures were achieved according to ASTM C 642-97 Standard [18-20] to determine the increased resistance towards water penetration in SCC. Cubic molds, $100 \mathrm{~mm}$ in size, were prepared both with and without pigment. After curing, the surfaces of the samples were allowed to dry, and their saturated masses were determined after immersion. For this purpose, the specimens were oven dried at $115 \pm 5^{\circ} \mathrm{C}$, and water absorption of the specimens was calculated.

The determination of abrasion resistance was conducted as per specification EN 1338 [21] on cube samples of $71 \pm$ $1.5 \mathrm{~mm}$ by using Bohme abrasion test abrader (Figure 2). This standard is highly suggested for the abrasion of concrete paving block applied on SCC specimens to be an alternative of ASTM C779. A great deal of researchers applied this method and achieved reliable results [22-25]. Before the test, the specimens were dried at first to constant mass at a temperature of $105 \pm 5^{\circ} \mathrm{C}$. In accordance with this standard, specimens were placed on the steel test disc which is of a $750 \mathrm{~mm}$ diameter rotating track, and the specimens were then exposed to grinding for 22 cycles under a constant load of $294 \pm 3 \mathrm{~N}$ and 30 cycles/min rotation speed. In the test series of steps, before the specimens were placed, standard abrasive of $20 \pm 0.5 \mathrm{~g}$ was poured on the disc; afterwards, the load was applied to the specimen and the aforementioned procedure was repeated for 16 periods by rotating the sample $90^{\circ}$ in each period that all of them consisting of 22 revolutions. The loss in mass was measured, and the decrease in volume due to abrasion was calculated in $\mathrm{cm}^{3} / \mathrm{cm}^{2}$. Abrasive dust used in this test was artificial corundum.

The water impermeability measurements of SCC mixtures were carried out on three testing specimens using the concrete impermeability test equipment as shown Figure 3, in compliance with German Code DIN-1048 [26]. $150 \mathrm{~mm}$ of standard cube samples were used, and SCC specimens were put on impermeability tester and tubes filled with regular water subsequently. Initially, scale readings of tubes were measured by applying water, and then the samples were placed under pressure and tested up to 1 bar for 24 hours, 3

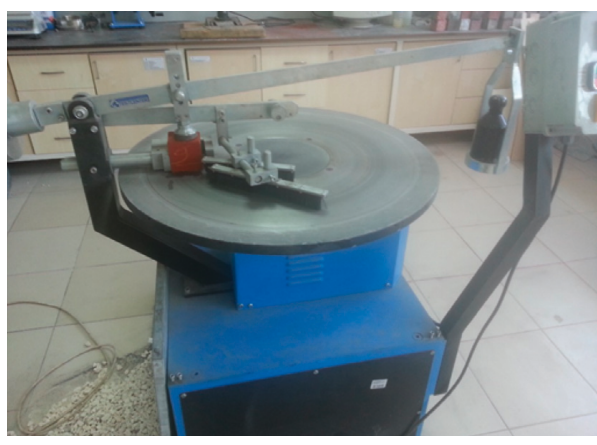

Figure 2: Bohme abrasion test apparatus.

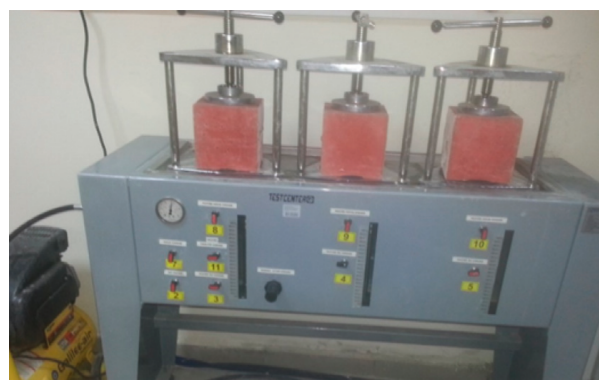

FIgURE 3: Impermeability test apparatus.

bars for 24 hours, and 7 bars for 24 hours to determine depth of water impermeability. After that, scale readings accomplished and the weight of the samples and the amount of water absorbed were calculated. At the end of the testing procedure, splitting test was applied on specimens to determine impermeability depth.

\section{Experimental Results and Discussion}

3.1. Properties of Fresh Concrete. The slump flow values for SCC with pigments immediately after the mixing process are presented by using the bar graph in Figure 4. Because of the conventional slump test is not appropriate to quantify the workability of SCC, the slump flow is used as a test method for SCC workability [27]. All series presented satisfactory flow values of at least $645 \mathrm{~mm}$ in terms of workability. By EFNARC, slump flows of $650 \mathrm{~mm}$ to $800 \mathrm{~mm}$ are typically required for SCC [17]. Most of the SCC series were satisfied with EFNARC specifications as satisfactory slump flows in the range of $645-725 \mathrm{~mm}$.

The series which contains pigments with varying amounts performed lower slump flow values than the pigment-free series. As pigment free series, M1 mixture had limestone powder and M1 mixture showed better performance than M2 mixture which contains maroon marble powder for slump flow values. It can be seen from Figure 4 that the results of slump flow tests reveal that in the series which contains larger quantities of pigments there is a further decrease in slump flow values compared to the pigmentfree series. M10 series did not exhibit satisfactory slump flows that are typically required for SCC by the Committee of EFNARC. This might be explained by the increased 


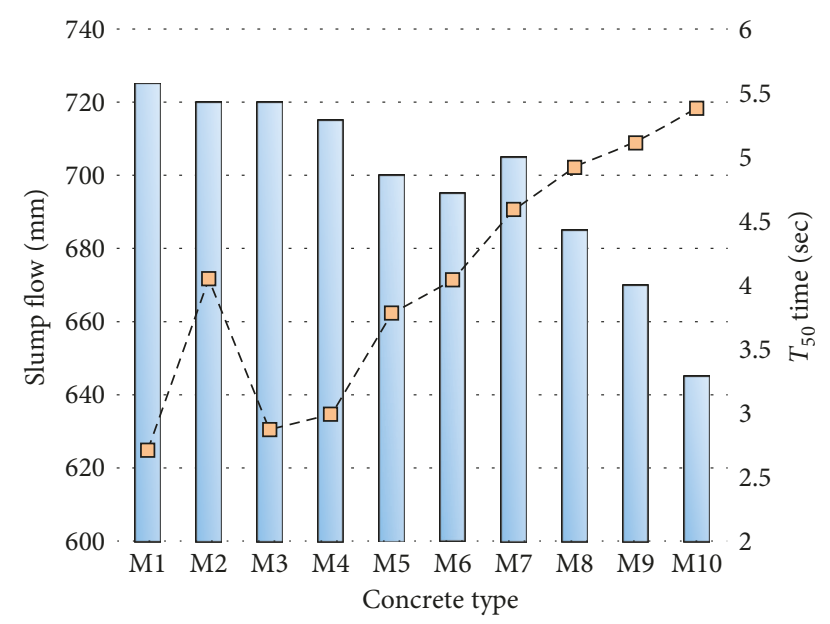

FIgURE 4: Slump flow and $T_{50}$ time of the SCC series.

pigment amounts that enhanced the water demand. The water content remained constant for all of the series in this study; however, pigment-free series needs less water and provides more slump flow. In terms of workability, the mixtures which contain pigments generally have shown worse performance than the pigment-free series.

The slump flow time for the SCC series was determined by measuring the time taken for the concrete to reach a spread diameter of $500 \mathrm{~mm}$ from the moment the slump cone is lifted up for all the series and was less than $5.38 \mathrm{~s}$, and most of the SCC series presented flow time values in the range of $2-5 \mathrm{~s}$ as shown in Figure 4 with the dashed line. The $T_{50}$ times and the slump flow tests that comply with that of the standard values given by EFNARC [17] were conducted to measure the fresh properties of SCC including filling ability.

Besides of the slump flow and $T_{50}$ time, $\mathrm{V}$-funnel test was also employed to assess the stability and flowability of the pigment additive series and pigment free series of SCC. The $\mathrm{V}$-funnel flow time values were in the range of 9-18s. For V-funnel time, EFNARC Committee suggests that $11 \mathrm{~s}$ and $15 \mathrm{~s}$ for lower and upper limits, respectively, are reasonable for producing the appropriate SCC. In Figure 5, experimental test results revealed that all SCC mixtures do not meet the permitted flow time requirements. Therefore, $\mathrm{V}$-funnel time above $15 \mathrm{~s}$ would be hard to handle and very cohesive. It can be from Figure 5, that when pigment ratio is increased cohesion of the mixtures are also increased. M1, M2, M3, M4, M5 and M6 series satisfied the suggestion of EFNARC Committee, but other series which contains larger quantities of pigments were very cohesive. It was also observed by other researchers that pigments improve the cohesion of the mortar and concretes $[6,28]$ and the addition of pigments might modify the cohesion and the flowability of the mixture.

In the L-box test, the ratio of heights at the two edges of $\mathrm{L}$ box, $T_{400}$ and $T_{800}$, demonstrates the passing and filling ability of SCC. The sensitivity of blocking is very high in this test method. When the L-box blocking ratio $\left(h_{2} / h_{1}\right)$ is below 0.8 , there can be generally a blocking risk of the SCC mixtures [17]. To be considered as an acceptable ratio for designing the functional SCC mixtures, a blocking ratio must be in the range of $0.8-1.00$. A maximum particle size of

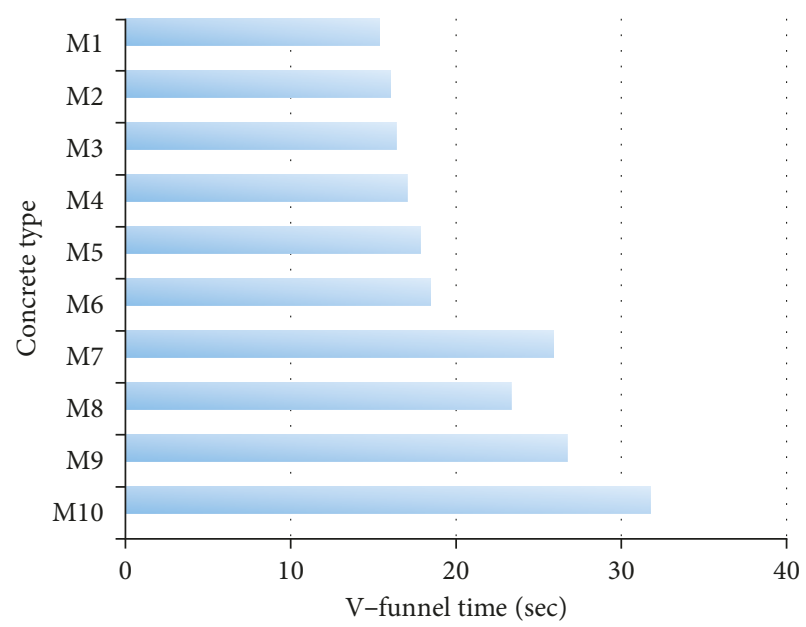

FIGURE 5: V-funnel time of the SCC series.

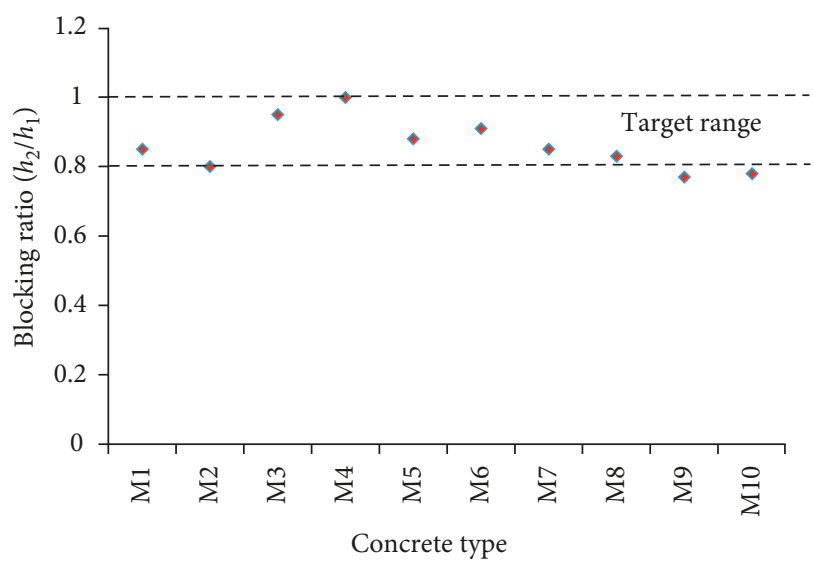

FIGURE 6: Blocking ratio of the SCC series.

$16 \mathrm{~mm}$ coarse aggregate was used in that study keeping away from blocking effect in this test, and most of the series of SCC have maintained the target range that is in accordance with EFNARC standards.

The blocking ratios of the series of SCCs produced with pigments or the series of without pigments are given in Figure 6 . The blocking ratio of the M4 mixture was 0.99 , and the blocking ratio of the M10 mixture was 0.78 . The yield stress of M10 mixture was high compared with other series because the M10 mixture includes more pigments than the other mixtures. When the pigment content has increased, pigment addition has negatively affected the blocking ratio due to simultaneous increase in viscosity. Nevertheless, it can be proved in this study that each series examined has adequate passing ability and filling capability in terms of selfcompactibility.

\subsection{Properties of Hardened Concrete}

3.2.1. Water Absorption. For all the mixtures, the hardened properties that were expressed as water absorption, compressive strength, and UPV at 3, 7, and 28 days and the 
TABLE 4: Water absorption values of SCC series.

\begin{tabular}{lccc}
\hline & \multicolumn{3}{c}{ Water absorption $(\%)$} \\
Mixture & 3 days & 7 days & 28 days \\
\hline M1 & 3.2509 & 2.879 & 2.801 \\
M2 & 3.2527 & 2.881 & 2.799 \\
M3 & 3.2520 & 3.059 & 3.028 \\
M4 & 3.2935 & 2.999 & 2.980 \\
M5 & 3.3100 & 3.066 & 3.091 \\
M6 & 3.3538 & 3.145 & 3.108 \\
M7 & 3.4841 & 3.177 & 3.100 \\
M8 & 3.6199 & 3.218 & 3.168 \\
M9 & 3.7106 & 3.310 & 3.225 \\
M10 & 3.8925 & 3.480 & 3.364 \\
\hline
\end{tabular}

density at 28 days. Table 4 report the mean of water absorption as determined from three specimens at three different curing times. As seen in Table 4, water absorption in the specimens submerged in water decreased over time in all the groups. This might have been due to the effect of the curing environment on SCC properties. The higher water absorption of the series was M10 series which contains the highest amount of pigment, and the use of limestone powder performed positive effect compared to maroon marble powder additive series. The use of small amount of pigments does not have a remarkable effect on water absorption properties owing to pigment filler effect. However, by comparing pigment-free specimens submerged in water, it seems that using larger quantities of pigments can increase water absorption of the SCC specimens. The increase in water absorption as the amount of pigment increases can explain inert effect of higher amounts of pigments, thus suggesting a system with a high void content, generated by the bad formation of the cementitious matrix owing to the insufficient hydration. But, all specimens satisfied the range of water absorption specified in ASTM Standard C 642-97 [18].

3.2.2. Compressive Strength. Figure 7 depicts the mean of compressive strength as defined on three specimens. Figure 7 presents that M1 and M2 series were pigment-free and other series were containing varying amounts of pigments. The effect of maroon marble powder and varying amounts of pigments on the compressive strength of SCCs at different ages was determined. The compressive strength values are in the range of $34.54-51.86 \mathrm{MPa}$ at 3 days. The lowest value belongs to M10 series and the highest one to M4 series. The compressive strength values were in the range of 44.03$61.64 \mathrm{MPa}$ at 28 days; M3 series was the highest one, and M10 series was the lowest one. Meanwhile, M3 series was the highest compressive strength value, and like in other curing times, M10 series was the lowest compressive strength value; SCC mixtures yielded a compressive strength of 51.97$72.98 \mathrm{MPa}$ at 28 days.

As seen in Figure 7, specimens amended with maroon marble powder exhibited higher compressive strengths at all curing ages than the larger quantities of pigmented series. For example, the compressive strength of the 7-day specimen of M2 series is about $59.35 \mathrm{MPa}$, which improves by $25 \%$ than those of the M10 series which contains the highest amount of

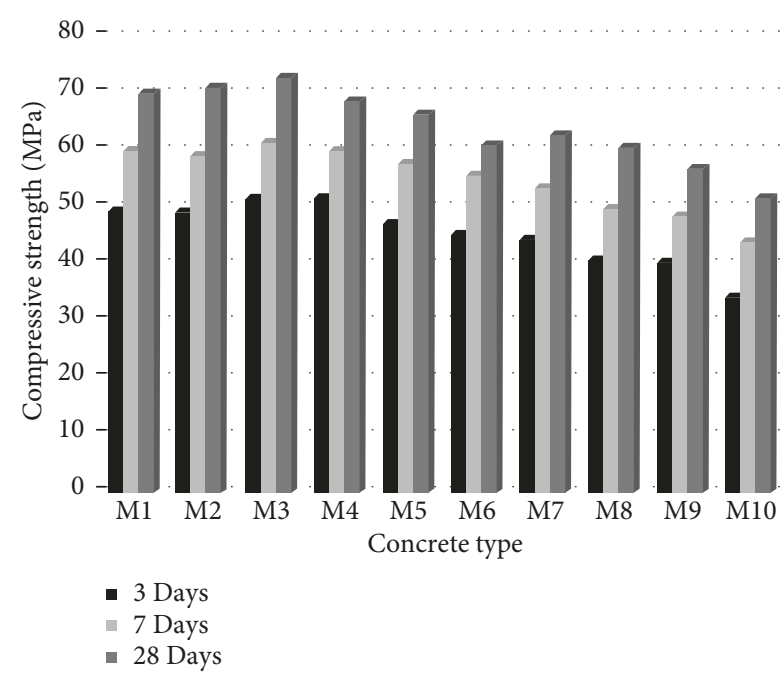

FIgURE 7: Compressive strength of SCC series at varying times.

pigment. However, M3 and M4 series that showed the highest performance at all the curing ages were containing less pigments, and this might be attributed that the use of less pigment affected the performance of SCC in positive way as filler effect. The decrease in compressive strength of the specimens containing larger quantities of pigments is probably owing to deposition of pigments in the interface between the coarse aggregates and the matrix. The use of higher amounts of pigments weakens the interface between the coarse aggregates, and the matrix acts as inert filler. The other reason of decrease in compressive strength is probably due to a high specific surface area of the pigment which is used in this study, and the water content remained constant for all of the series. This suggests that, within the cementitious composite, its particles adsorb water. The concrete in question is classified as dried and has a low water-cement ratio, having naturally low water availability for hydration reactions of cement's silicates and aluminates. Thus, the addition of pigment becomes actually detrimental to the compressive strength gain system, as it further reduces even more the water availability for these reactions [29]. López et al. investigated advantages of mortarbased design for coloured SCC and observed that SCC mixtures made with pigments have lower compressive strength than those made with pigment-free mixture (reference mixture) [6]. Karaguler and Sungur found that using of larger quantities of pigments decreased compressive strength of coloured SCC irrespective of the pigments used in different types or different amounts [30]. Similar results on the decrease of compressive strength by using pigments were reported by other researchers $[29,31]$. Results of this study presented that although the use of larger quantities of pigments decreases the compressive strength, however, the use of small quantities of pigment causes slight increase in compressive strength.

3.2.3. Density and Ultrasonic Pulse Velocity. Table 5 shows density and UPV values of SCC series. The trend in compressive strength is similar to that in UPV. There was a simultaneous development that UPV values increased as 
TABle 5: UPV and density of the SCC series.

\begin{tabular}{lcccc}
\hline Mixtures & UPV $(\mathrm{m} / \mathrm{s})$ & \multicolumn{2}{c}{ Density $\left(\mathrm{kg} / \mathrm{m}^{3}\right)$} \\
28 days
\end{tabular}

TABLE 6: Abrasion depths and mass losses of SCC series.

\begin{tabular}{|c|c|c|c|c|c|c|c|c|c|c|}
\hline Mixtures & M1 & M2 & M3 & M4 & M5 & M6 & M7 & M8 & M9 & M10 \\
\hline \multicolumn{11}{|l|}{7 days (curing time) } \\
\hline Depth of abrasion $(\mathrm{mm})$ & 0.90 & 1.1 & 1.3 & 1.2 & 1.5 & 1.5 & 2.0 & 2.1 & 2.2 & 2.0 \\
\hline Mass loss (\%) & 0.95 & 0.97 & 0.98 & 0.96 & 1.13 & 1.25 & 1.26 & 1.46 & 1.73 & 2.34 \\
\hline \multicolumn{11}{|l|}{28 days (curing time) } \\
\hline Depth of abrasion (mm) & 0.90 & 1.3 & 0.90 & 1.1 & 1.2 & 1.0 & 1.5 & 2.1 & 2.0 & 1.8 \\
\hline Mass loss (\%) & 0.90 & 0.92 & 0.91 & 0.89 & 1.11 & 1.18 & 1.21 & 1.38 & 1.59 & 2.12 \\
\hline
\end{tabular}

compressive strength values increased for all the series. As a general acceptance, UPV can be used to evaluate the internal structure of concretes nondestructively. Experimental test results proved that there was a very strong correlation between UPV and the compressive strength of SCC series. Correlation coefficient of $R^{2}$ was found to be in the order of $95 \%$. The sound transmission velocity is a function of the density of the material in compliance with the sound propagation theory of solids [32], and it is observed that there is a concurrent development between UPV and density as well as compressive strength.

\subsection{Properties of Durability}

3.3.1. Abrasion Resistance. For certain types of constructed facilities such as concrete parquets that are commonly used in urbanization projects for road paving, abrasion resistance is an important feature to achieve long-term durability. Together with the depth of abrasion and mass loss at $7 \mathrm{~d}$ and $28 \mathrm{~d}$, abrasion values of coloured SCC mixtures summarised in Table 6 were obtained from the abrasion test with grinding disk by Bohme. The presented depth of abrasion and mass loss damage results are the average values of abrasion of three test specimens. At 7 days, SCC mixtures yielded a mass loss of $0.95 \%-2.34 \%$ and yielded an abrasion depth of $0.9-2.2 \mathrm{~mm}$ at the end of abrasion wear test. Meanwhile, the abrasion depth values were within the range of $0.90-$ $2.10 \mathrm{~mm}$ and mass loss values were within the range of $0.89 \%-2.12 \%$ at 28 days. As seen in Table 6, M1 series showed the best and contained both the lowest mass loss values and lowest abrasion depth values when compared with other SCC series at $7 \mathrm{~d}$ and $28 \mathrm{~d}$. It was also noticed that mass loss values and abrasion depth values reduced as the curing time increased for all SCC series. Experimental test results expressed that the abrasion resistance of SCC was positively affected by curing time which contains maroon marble powder and pigmented series which contains varying amounts of iron oxide pigments.

Abrasion resistance test results demonstrated that the mass loss rate of SCC gradually increased with the increasing of pigments. Generally speaking, slightly higher resistance to wear was displayed by the pigment-free series of SCC. It is obvious that SCC series having higher compressive strength, in general, possessed lower abrasion values. It was also examined by other researchers that there was a direct correlation between abrasion resistance and compressive strength [33-37]. However, when compared to the pigment-free series, the use of larger quantities of pigment also provided decrease in abrasive resistance. The decrease in abrasion resistance might be attributed to providing the formation of less dense and more porous microstructure system in SCC when larger quantities of pigments are used through its chemical and physical effects both during the fresh and hardened states. So, it becomes critical for abrasion resistance of SCC series due to the formation of less dense and more porous microstructure character.

3.3.2. Impermeability. A measure of the resistance of SCC series against the water impermeability is calculated by the impermeability test by applying pressure over a period of 72 hours. By obtaining the average of three specimens, the maximum depths of water penetration for pigment-free and pigment additive SCC mixtures are given in Table 7.

Table 7 presents that SCC mixtures yielded a water impermeability depth of $4.47-7.28 \mathrm{~mm}$. The results reported that M8 series performed the lowest water impermeability 
TABLE 7: Water impermeability depths of SCC series.

\begin{tabular}{|c|c|c|c|c|c|c|c|c|c|c|}
\hline Mixtures & M1 & M2 & M3 & M4 & M5 & M6 & M7 & M8 & M9 & M10 \\
\hline Water impermeability depths (mm) & 7.28 & 7.09 & 7.30 & 7.48 & 6.31 & 6.16 & 5.05 & 4.47 & 5.00 & 5.15 \\
\hline
\end{tabular}

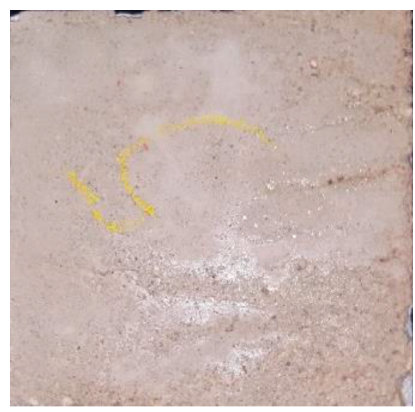

(a)

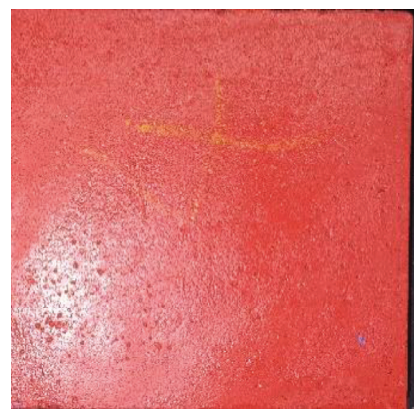

(e)

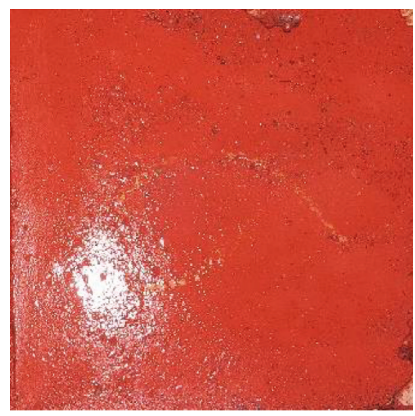

(i)

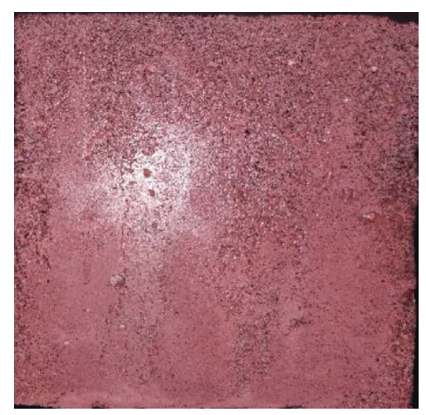

(b)

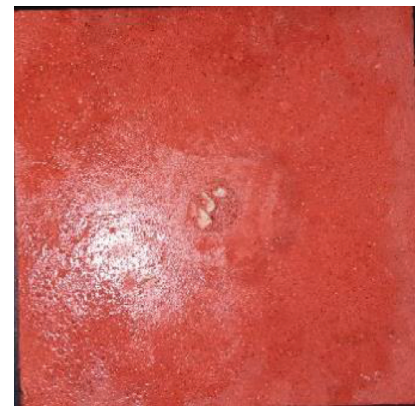

(f)

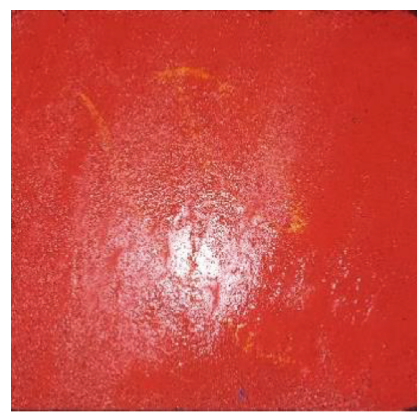

(j)

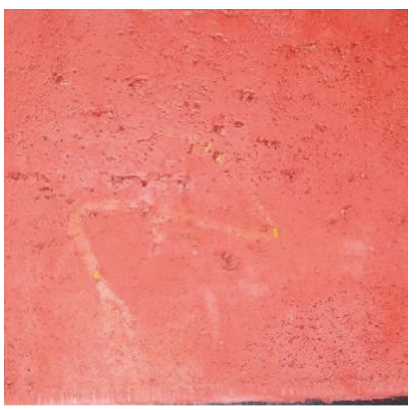

(c)

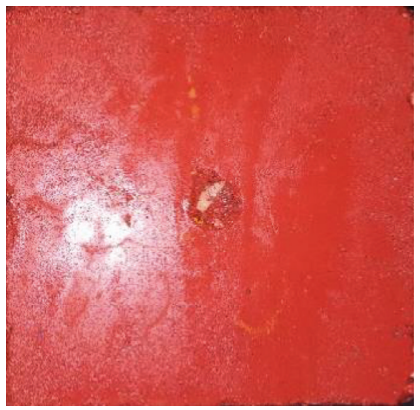

(g)

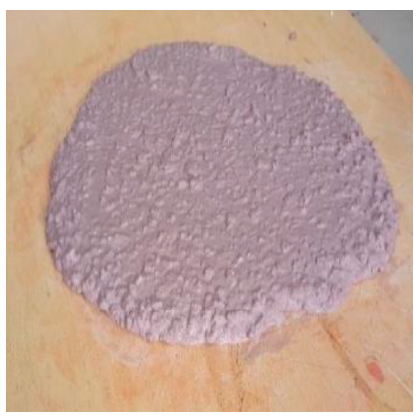

(k)

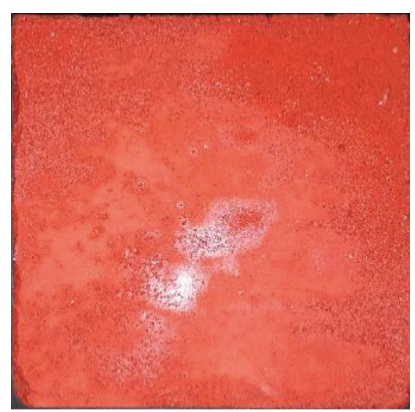

(d)

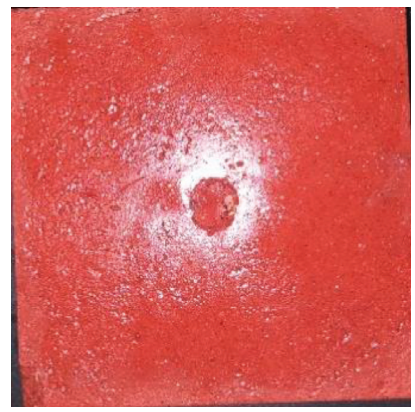

(h)

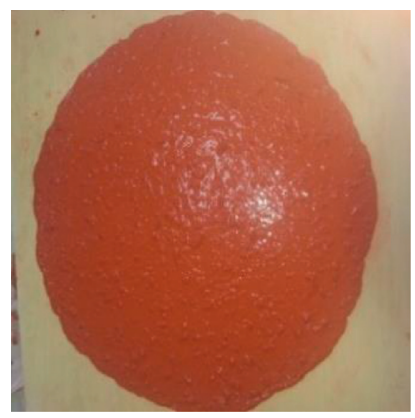

(1)

FIGURE 8: Colour parameters of hardened SCC series from M1 series to M10 series and slump flow spread diameter of some fresh SCC series (M2 series and M4 series). (a) M1 (LP-pigment free), (b) M2 (MMP-pigment free), (c) M3 (1\% pigment), (d) M4 (2\% pigment), (e) M5 (3\% pigment), (f) M6 (4\% pigment), (g) M7 (5\% pigment), (h) M8 (6\% pigment), (i) M9 (7\% pigment), (j) M10 (8\% pigment), (k) M2 (MMP-pigment free), and (l) M4 (2\% pigment).

depth. Furthermore, in the case of using higher amounts of pigments, the increase in the pigment amount has also decreased impermeability depth slightly. Nevertheless, all the series did not allow passing water due to filler effect by filling the pores.

Pigments are commonly used to produce coloured SCC, and iron oxide pigment can also be used to slightly reduce the water impermeability and water absorption properties of concrete by filling the pores. Improvements were noted at all the series, clearly demonstrating that using a higher amount of pigment is slightly making the coloured SCC less impermeable.
3.4. Visual Inspection. Figure 8 illustrates a sample of each series which were produced for this study altogether. By observing Figure 8, a comprehensive visual inspection was performed to evaluate the performance of the pigments used in varying amounts in terms of colour intensity and on the usability of maroon marble powder as a natural waste which contains no synthetic dyes to colour the SCC. SCC series was compared in terms of colour intensity visually. To achieve a slightly similar colour intensity, relative tinting power was evaluated by comparing the iron oxide red pigment and maroon marble powder. Figure 8 shows the variation of colour parameters of hardened SCC series and slump flow 
spread diameter of some fresh SCC series. When the pigment content decreased, there can be seen a lightness on the surface of hardened SCC series. The use of larger quantities of synthetic iron oxide pigments increased colour intensity and tinting power of SCC mixtures. M2 mixtures exhibited more colour intensity compared to M3, M4, and M5 series visually.

\section{Conclusions}

This study summarizes an extensive experimental program on coloured SCC by using maroon marble powder as a natural dying agent and varying amounts of pigments. Some conclusions can be drawn from the experimental results:

(i) In terms of workability, most of the series of SCC have maintained the target range that is in accordance with EFNARC standards.

(ii) The higher water absorption of the series was containing the highest amount of pigment.

(iii) The use of small amount of pigments causes slight increase in compressive strength when compared to that of pigment-free series.

(iv) SCC mixtures yielded a mass loss of $0.89 \%-2.12 \%$ and yielded an abrasion depth of $0.9 \mathrm{~mm}-2.1 \mathrm{~mm}$ at the end of abrasion wear test at $28 \mathrm{~d}$.

(v) SCC mixtures yielded a water impermeability depth of 4.47-7.28 mm, and all the series of SCC's did not allow passing water through concrete.

The results presented in this paper reveal that it is possible to successfully utilize maroon marble powder in producing coloured SCC and pigments used in amounts more than $3 \%$ generally do not improve coloured SCC properties.

\section{Conflicts of Interest}

The author declares that there are no conflicts of interest.

\section{References}

[1] G. T. Iris, G. F. Belén, M. A. Fernando, and C. L. Diego, "Selfcompacting recycled concrete: relationships between empirical and rheological parameters and proposal of a workability box," Construction and Building Materials, vol. 143, pp. 537-546, 2017.

[2] S. D. Hwang, K. H. Khayat, and O. Bonneau, "Performancebased specifications of self-consolidating concrete used in structural applications," ACI Materials Journal, vol. 103, no. 2, pp. 121-129, 2006.

[3] H. Okamura and M. Ouchi, "Self-compacting high performance concrete," Progress in Structural Engineering and Materials, vol. 1, no. 4, pp. 378-383, 1998.

[4] K. Ma, J. Feng, G. Long, Y. Xie, and X. Chen, "Improved mix design method of self-compacting concrete based on coarse aggregate average diameter and slump flow," Construction and Building Materials, vol. 143, pp. 566-573, 2017.

[5] K. Ozawa, "Development of high performance concrete based on the durability design of concrete structure," in Proceedings of The Second East Asia-Pacific Conference on Structural Engineering and Construction (EASEC-2), pp. 445-450, Chiang Mai, Thailand, January 1989.

[6] A. López, J. M. Tobes, G. Giaccio, and R. Zerbino, "Advantages of mortar-based design for coloured self-compacting concrete," Cement and Concrete Composites, vol. 31, no. 10, pp. 754-761, 2009.

[7] I. B. Topcu, T. Bilir, and T. Uygunoglu, "Effect of waste marble dust content as filler on properties of self-compacting concrete," Construction and Building Materials, vol. 23, no. 5, pp. 1947-1953, 2009.

[8] Turkish Ministry of Energy and Natural Resources, Marble Report, Turkish Ministry, Ankara, Turkey, 2016.

[9] M. Uysal, K. Yilmaz, and M. Ipek, "The effect of mineral admixtures on mechanical properties, chloride ion permeability and impermeability of self-compacting concrete," Construction and Building Materials, vol. 27, no. 1, pp. 263270, 2012.

[10] K. E. Alyamac, E. Ghafari, and R. Ince, "Development of ecoefficient self-compacting concrete with waste marble powder using the response surface method," Journal of Cleaner Production, vol. 144, pp. 192-202, 2017.

[11] D. M. Sadek, M. M. El-Attar, and H. A. Ali, "Reusing of marble and granite powders in self-compacting concrete for sustainable development," Journal of Cleaner Production, vol. 121, pp. 19-32, 2016.

[12] R. Sarkar, S. K. Das, P. K. Mandal, and H. S. Maiti, "Phase and microstructure evolution during hydrothermal solidification of clay-quartz mixture with marble dust source of reactive lime," Journal of the European Ceramic Society, vol. 26, no. 3, pp. 297-304, 2006.

[13] M. Y. Celik and E. Sabah, "Geological and technical characterization of Iscehisar (Afyon-Turkey) marble deposits and the impact of marble waste on environmental pollution," Journal of Environmental Management, vol. 87, no. 1, pp. 106-116, 2008.

[14] H. Akbulut and C. Gurer, "Use of aggregates produced from marble quarry waste in asphalt pavements," Building and Environment, vol. 42, no. 5, pp. 1921-1930, 2007.

[15] K. E. Alyamac and R. Ince, "A preliminary concrete mix design for SCC with marble powders," Construction and Building Materials, vol. 23, no. 3, pp. 1201-1210, 2009.

[16] H. Y. Aruntas, M. Guru, M. Dayi, and I. Tekin, "Utilization of waste marble dust as an additive in cement production," Materials and Design, vol. 31, no. 8, pp. 4039-4042, 2010.

[17] EFNARC, Specification and Guidelines for Self-Compacting Concrete, EFNARC, Surrey, UK, 2002.

[18] ASTM Standard C 642-97, Standard Test Method for Density, Absorption, and Voids in Hardened Concrete, (C 642-97), American Society for Testing and Materials, West Conshohocken, PA, USA, 1997.

[19] W. Piasta and B. Zarzycki, "The effect of cement paste volume and $\mathrm{w} / \mathrm{c}$ ratio on shrinkage strain, water absorption and compressive strength of high performance concrete," Construction and Building Materials, vol. 140, pp. 395-402, 2017.

[20] N. H. Balam, D. Mostofinejad, and M. Eftekhar, "Effects of bacterial remediation on compressive strength, water absorption, and chloride permeability of lightweight aggregate concrete," Construction and Building Materials, vol. 145, pp. 107-116, 2017.

[21] European Standard, EN 1338, Concrete Paving BlocksRequirements and Test, Methods, 2003. 
[22] S. Yazici and G. Inan, "An investigation on the wear resistance of high strength concretes," Wear, vol. 260, no. 6, pp. 615-628, 2006.

[23] A. Cavdar and S. Yetgin, "Investigation of abrasion resistance of cement mortar with different pozzolanic compositions and subjected to sulfated medium," Construction and Building Materials, vol. 24, no. 4, pp. 461-470, 2010.

[24] A. Kilic, C. D. Atis, A. Teymen, O. Karahan, F. Ozcan, and C. Bilim, "The influence of aggregate type on the strength and abrasion resistance of high strength concrete," Cement and Concrete Composites, vol. 30, no. 4, pp. 290-296, 2008.

[25] R. Siddique, K. Kapoor, E. H. Kadri, and R. Bennacer, "Effect of polyester fibres on the compressive strength and abrasion resistance of HVFA concrete," Construction and Building Materials, vol. 29, pp. 270-278, 2012.

[26] DIN 1048, Determination of Water Impermeability, German Standards, 1978.

[27] B. Felekoglu, S. Turkel, and B. Baradan, "Effect of water/cement ratio on the fresh and hardened properties of self-compacting concrete," Building and Environment, vol. 42, no. 4, pp. 1795-1802, 2007.

[28] A. López, J. M. Tobes, C. Torrijos, B. Barragán, G. Giaccio, and R. Zerbino, "Effect of pigment on the rheological properties," in Proceedings 5th International RILEM Symposium on SelfCompacting Concrete, pp. 309-314, Construction Press, Ghent, Belgium, 2007.

[29] P. S. X. Alcantara and A. C. Nóbrega, "Colored concrete interlocking blocks with addition of red ceramic waste for iron oxide pigments reduction," in Proceedings of the Construction for Sustainability-Green Materials and Technologies Nocmat 2015, pp. 1-11, Winnipeg, Manitoba, Canada, August 2015.

[30] M. Karaguler and S. Sungur, "The effect of pigments in the use of coloured self compacting concrete," in Proceedings of the 7th National Concrete Symposium, pp. 55-64, Istanbul, Turkey, November 2007.

[31] H. S. Lee, J. Y. Lee, and M. Y. Yu, "Influence of inorganic pigments on the fluidity of cement mortars," Cement and Concrete Research, vol. 35, no. 4, pp. 703-710, 2005.

[32] R. S. Carcano and E. I. Moreno, "Evaluation of concrete made with crushed limestone aggregate based on ultrasonic pulse velocity," Construction and Building Materials, vol. 22, no. 6, pp. 1225-1231, 2008.

[33] N. Kabay, "Abrasion resistance and fracture energy of concretes with basalt fiber," Construction and Building Materials, vol. 50, pp. 95-101, 2014.

[34] S. Kumar, R. C. Gupta, and S. Shrivastava, "Strength, abrasion and permeability studies on cement concrete containing quartz sandstone coarse aggregates," Construction and Building Materials, vol. 125, pp. 884-891, 2016.

[35] P. K. Acharya and S. K. Patro, "Strength, sorption and abrasion characteristics of concrete using ferrochrome ash (FCA) and lime as partial replacement of cement," Cement and Concrete Composites, vol. 74, pp. 16-25, 2016.

[36] R. Siddique, "Compressive strength, water absorption, sorptivity, abrasion resistance and permeability of selfcompacting concrete containing coal bottom ash," Construction and Building Materials, vol. 47, pp. 1444-1450, 2013.

[37] A. Kilıc, C. D. Atis, A. Teymen et al., "The influence of aggregate type on the strength and abrasion resistance of high strength concrete," Cement and Concrete Composites, vol. 30, no. 4, pp. 290-296, 2008. 


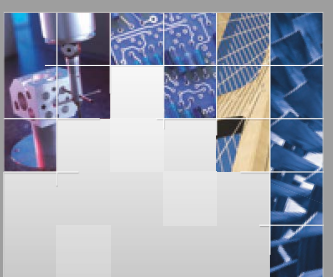

\section{Enfincering}
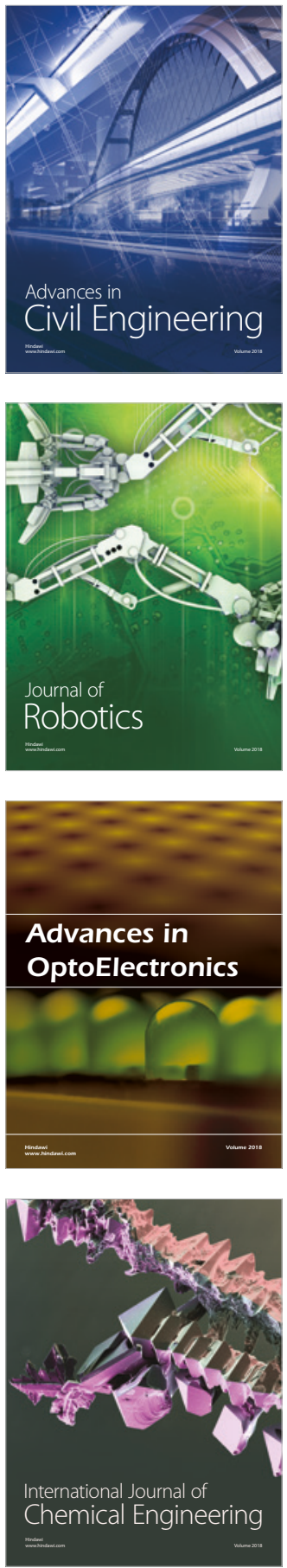

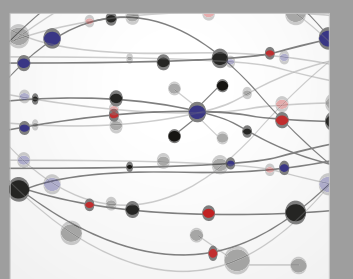

\section{Rotating \\ Machinery}

The Scientific World Journal

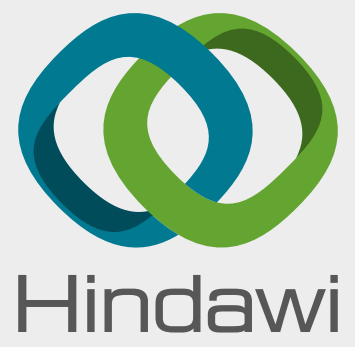

Submit your manuscripts at

www.hindawi.com
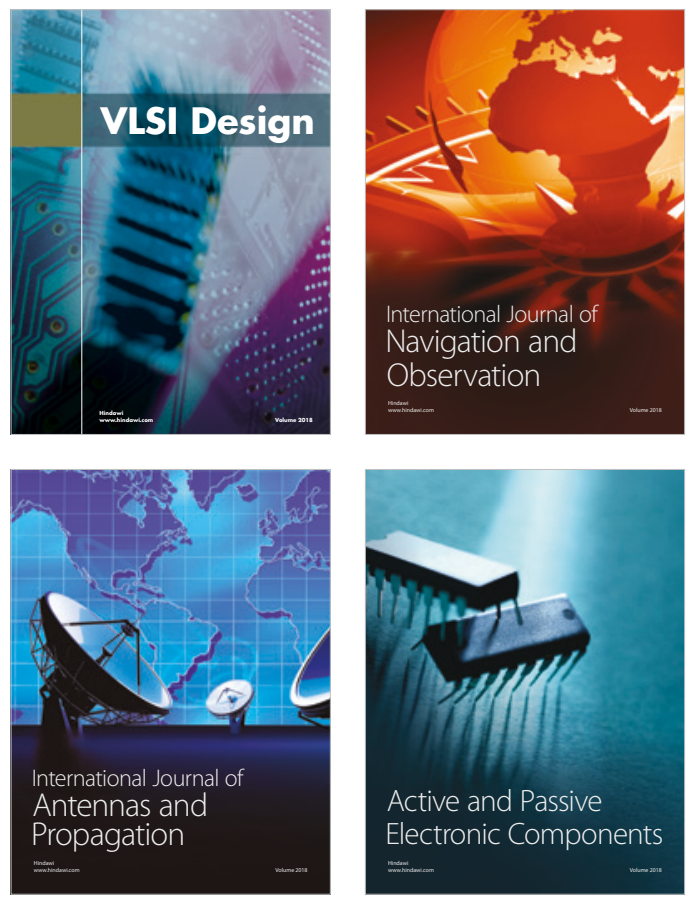
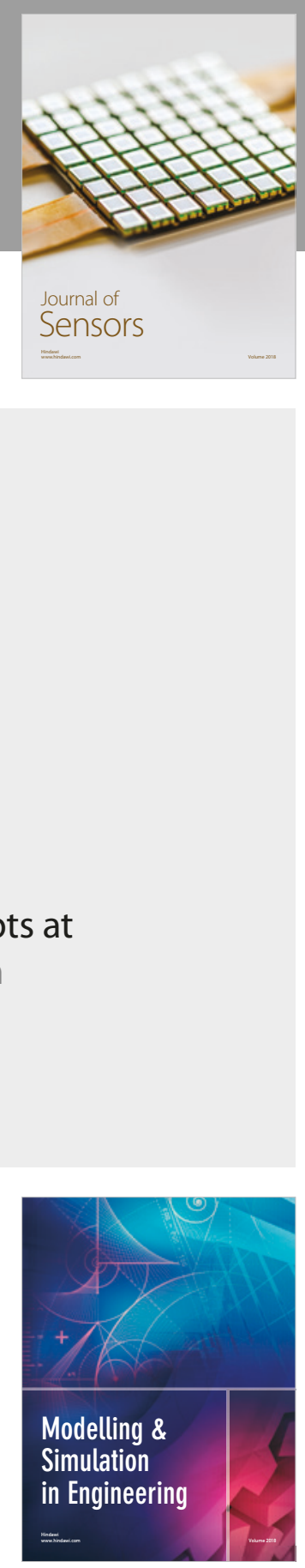

\section{Advances \\ Multimedia}
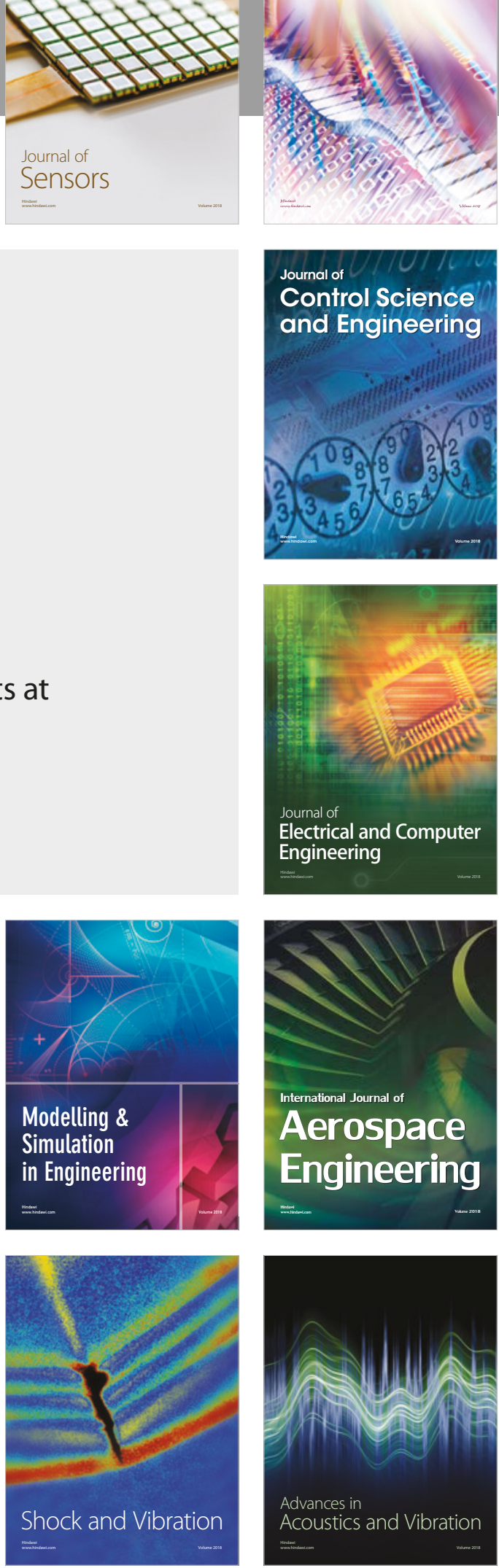